\title{
Plasma prolactin concentrations and cyclic activity in pony mares during parturition and early lactation*
}

\author{
K. Worthy, R. Escreet†, J. P. Renton†, P. D. Eckersall, T. A. Douglas and \\ D. J. Flint $\ddagger$
}

Departments of Veterinary Clinical Biochemistry and + Reproduction and Surgery, University of Glasgow Veterinary School, Garscube Estate, Bearsden, Glasgow G61 IQH, and $\ddagger$ Hannah Institute for Research in Dairying, Ayr KA6 $5 H L, U . K$.

\begin{abstract}
Summary. Five pony mares were blood sampled during late pregnancy, foaling and early lactation. An homologous assay for horse prolactin was used to measure plasma prolactin concentrations in these samples. Regular estimates of cyclic activity were also made. Plasma prolactin concentrations rose markedly in the last week of pregnancy and remained high although variable in early lactation, before declining to basal levels by 1-2 months post partum. All mares showed a post-partum oestrus $7.0 \pm 0.9$ days after parturition. One mare whose foal died shortly after birth showed a rapid decline in plasma prolactin values after death of the foal and an early oestrous period (4 days after parturition). The pattern of prolactin changes reported for the mare are in agreement with those reported for other mammalian species.
\end{abstract}

\section{Introduction}

Prolactin appears to play a crucial role in the process of lactation in most mammalian species so far studied. In many eutherian species, a marked rise in circulating prolactin concentrations is seen in the last week of pregnancy (Buttle, Forsyth \& Knaggs, 1972; Fell et al., 1972; Shiu, Kelly \& Friesen, 1973; McNeilly \& Friesen, 1978). It is thought that this rise in prolactin is at least partly responsible for the final stages of development of the mammary gland and the initiation of milk secretion (Cowie, Forsyth \& Hart, 1980). After the young are born, large pulses of prolactin continue to be released from the pituitary in response to suckling, and these appear to be important in maintaining galactopoiesis (Davis, Reichert \& Niswender, 1971; Concannon, Butler, Hansel, Knight \& Hamilton, 1978). As the young begin to eat more and suck less, prolactin release gradually declines.

Reports of circulating prolactin concentrations in the mare during pregnancy and lactation have been few, and have failed to detect any significant changes in the pattern of prolactin secretion during these events (Nett, Holtan \& Estergreen, 1975a, b). However, previous attempts to measure plasma prolactin in the horse have used heterologous radioimmunoassays based on a sheep prolactin system and using sheep prolactin as tracer and standard. The present study aimed to study in more detail the changes in prolactin concentrations in the mare during foaling and lactation, using an homologous radioimmunoassay for horse prolactin.

In addition to its role in lactation itself, high prolactin values have been strongly implicated in delaying the return of oestrous (or menstrual) cycles after parturition in animals of several species including sheep (Kann, Martinet \& Schirar, 1978) and women (McNeilly, 1980). However, the majority of mares show at least one fertile oestrous cycle almost immediately after foaling, although the fertility of this ovulation compared to those during the normal breeding season has

*Reprint requests to Dr J. P. Renton. 
been questioned (Sullivan, Turner, Self, Gutteridge \& Bartlett, 1975), and in many mares cyclic activity after the first post-partum oestrus is abnormal or absent. In order to improve the chances of conception as early as possible after foaling, the underlying hormonal events must be understood. Another aim of the study was therefore to investigate any connection between plasma prolactin concentrations and the occurrence of oestrous cycles in the mare after parturition.

\section{Materials and Methods}

\section{Animals}

Five pregnant pony mares of various ages (5-22 years old), due to foal in October to December, were blood-sampled daily during the last few weeks of pregnancy and during the first 4-6 weeks of lactation. Less frequent blood samples were taken thereafter. All blood samples were collected in the morning.

Daily assessments of oestrous behaviour were made for all the mares by teasing with a stallion. Regular estimates of follicular development by means of rectal palpation of the ovaries were also made. Plasma progesterone determinations were carried out to confirm cyclic activity. The occurrence of cyclic activity in the mares after parturition was assessed on the joint data for oestrous behaviour, progesterone status and changes in the size of the largest follicle.

After foaling, the foals were allowed to suck at will and kept with the dam until the end of the experiment. Mares were housed and fed on hay ad libitum together with a ration of concentrates. Two of the mares (Mares 4 and 5) were mated at the first post-partum oestrus, but the others (Mares 1-3) were not.

\section{Hormone determinations}

Prolactin. Plasma prolactin concentrations were measured by using an homologous doubleantibody radioimmunoassay with a highly purified horse prolactin as standard and a specific antiserum raised against this standard. The horse prolactin preparation was purified from horse pituitaries and characterized by Li \& Chung (1983); it had a biological potency of $42 \mathrm{i} . \mathrm{u} . / \mathrm{mg}$ in the pigeon crop-sac assay. The antiserum, standard and assay methodology were as described by Roser, Chang, Papkoff \& Li (1984) with the following modifications to the method. The hormone was iodinated by the use of a solid-phase lactoperoxidase-glucose oxidase system (Habener, Rosenblatt, Dee \& Potts, 1979). This technique gave a stable tracer with $20-30 \%$ binding at an initial dilution of the primary antiserum of 1:15000. The bound fraction of the ${ }^{125}$ I-labelled prolactin was precipitated by using a polyethylene glycol (PEG)-assisted double-antibody system, with the addition of $2.5 \%$ PEG (final concentration) and incubation for $2 \mathrm{~h}$ at room temperature before centrifugation and separation of the supernatant.

The antiserum was tested by Roser et al. (1984), and cross-reactions were found to be $<1 \%$ for horse GH, TSH, LH and FSH. The inter-assay coefficient of variation, based on several plasma pools included in each of a number of assays, was $17.5 \%$, and the intra-assay coefficient of variation for randomly selected duplicate pairs was 5·5\%. An inhibition curve for a plasma pool measured at three different dilutions ran parallel to the standard curve. Known amounts $(0.08-2.5 \mathrm{ng})$ of the horse prolactin standard were assayed after addition to a mare plasma pool. After adjustment for the prolactin concentration measured in the pool alone, the mean \pm s.e.m. recovery figure was $107 \pm 6 \%(n=14)$. The limit of sensitivity of the assay, defined as the value at twice the standard deviation of blank values, was $1.5 \mathrm{ng} / \mathrm{ml}$.

Progesterone. These measurements were carried out using the radioimmunoassay method of Munro, Renton \& Butcher (1979). The intra- and inter-assay coefficients of variation were $<15 \%$, and the limit of sensitivity was $0.3 \mathrm{ng} / \mathrm{ml}$. 


\section{Results}

\section{Foaling}

All mares foaled normally and 4/5 foals survived and developed normally. One foal (Mare 5) developed septicaemia within the first day of life and died shortly afterwards.

\section{Resumption of cyclic activity post partum}

All mares showed a post-partum oestrus beginning 4-9 days after foaling which varied in length from 2 to 9 days, but it was notable that in Mare 5, which lost her foal, oestrus began earliest and lasted longest (Days 4-13 post partum). Palpation of the ovaries per rectum indicated that in each mare at least one large $(2 \cdot 5-5 \cdot 5 \mathrm{~cm})$ follicle developed at this time, and progesterone measurements showed that luteal tissue developed in the ovaries of all mares after the oestrous period.

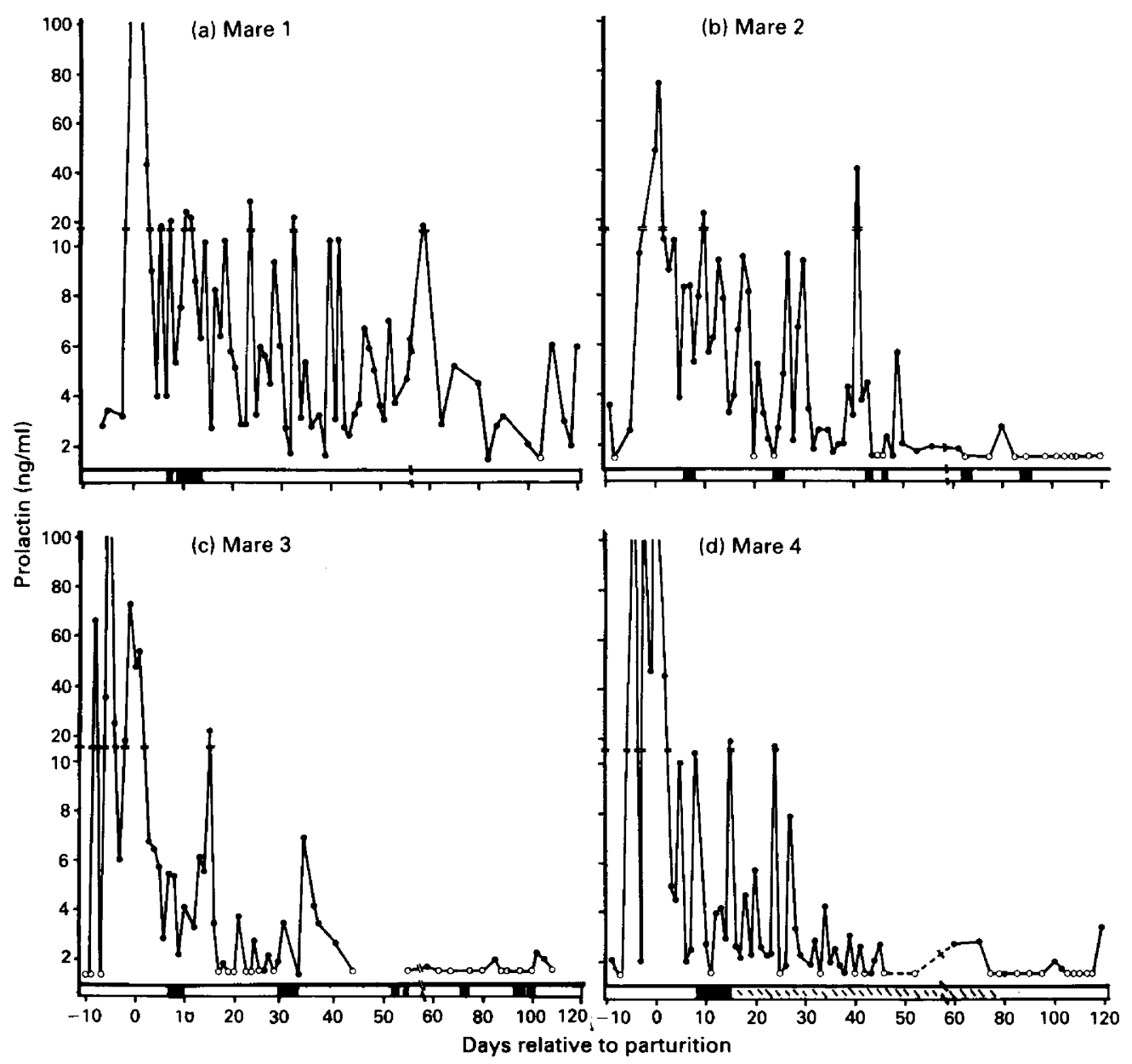

Fig. 1. Plasma prolactin concentrations (O) and cyclic activity in 4 mares with a normal lactation. The shaded areas indicate the days that oestrous behaviour was shown; the hatched areas indicate that the mare was pregnant at this time. Samples below the limit of sensitivity of the assay are indicated by open symbols $(O)$. 


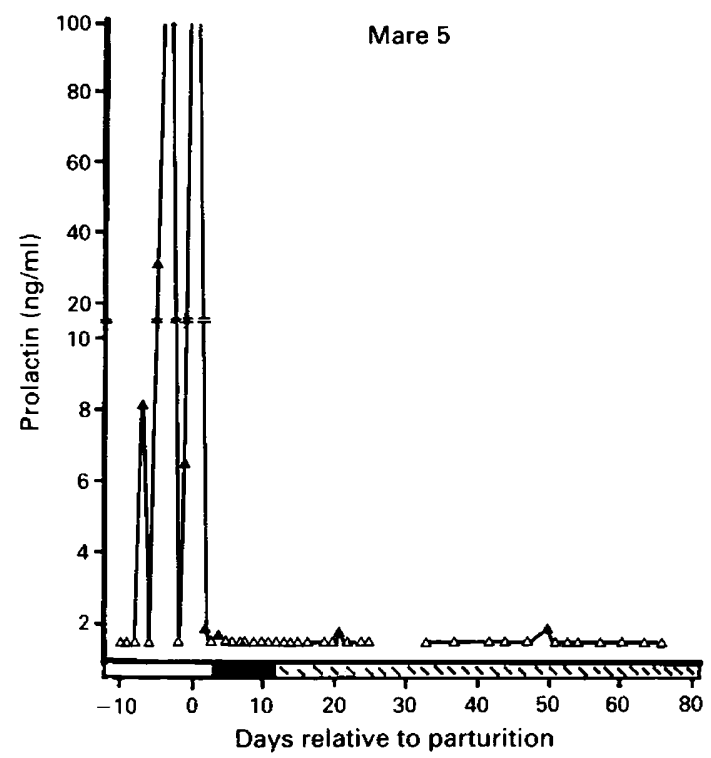

Fig. 2. Plasma prolactin concentrations $(\boldsymbol{A})$ and cyclic activity in Mare 5 whose foal died on Day 1 post partum. The shaded areas indicate when oestrous behaviour was shown, and the hatched areas the time when the mare was pregnant. Samples with undetectable levels of prolactin are indicated by open symbols $(\triangle)$.

Of Mares 1-3, which were not mated, only Mare 1 failed to show regular oestrous cycles after the first post-partum cycle. Mares 4 and 5 were mated and became pregnant; Mare 4 lost her pregnancy mid-term, but Mare 5 carried to term.

\section{Prolactin concentrations}

Figure 1 shows the change in prolactin concentrations in 4 of the mares during late pregnancy and early lactation. In all the mares prolactin concentrations appeared to be quite low 10 days before parturition. At about Day -5 relative to foaling, but at varied times for individual mares, there was a rapid and very marked increase in prolactin concentrations. This rise was sustained during parturition and up until Days 1-5 post partum. A high but uneven pattern of prolactin release was then detected, with a gradual decrease in prolactin concentrations until levels became basal at Days 40-70 post partum. Although there was a great deal of variation amongst the mares in the post-partum pattern of prolactin release, one mare (Mare 1) had consistently higher prolactin concentrations throughout the period of lactation studied, compared to the other mares. This was coupled with an absence of oestrous cycles after her first post-partum cycle.

Figure 2 shows prolactin concentrations in the mare which lost her foal at Day 1 post partum (Mare 5). Although she showed the normal pre-partum prolactin rise and high concentrations during foaling, as soon as the foal was removed prolactin concentrations became basal and remained so.

\section{Discussion}

Using an homologous RIA for horse prolactin, marked increases in plasma prolactin concentrations were found in pony mares in the last week of pregnancy. Large peaks of prolactin release 
were also detected during the first 1-2 months of lactation. The pattern of changes in circulating prolactin reported here for the late pregnant and lactating mare are very similar to those reported for a number of mammalian species.

Experiments in pigs (Nordskog \& Clark, 1945), cows (Schams, Reinhardt \& Karg, 1972) and sheep (Kann, 1976) using bromocriptine-induced inhibition of prolactin release have shown that the release of prolactin during the final stages of pregnancy is necessary for completion of mammary development and the initiation of milk secretion. The similar timing of the prolactin changes in the mare suggests that this may also be true for the horse. Furthermore, the rise in prolactin occurs at a time when there is a rapid increase in the quantity of milk constituents secreted by the mare (Forsyth, Rossdale \& Thomas, 1975). In non-ruminant species such as rabbits (Taylor \& Peaker, 1975) and rats (Shaar \& Clemens, 1972) high levels of prolactin are also essential if adequate milk production is to continue. However, in ruminants prolactin secretion can be completely suppressed once lactation is established without materially affecting the level of milk secretion. In these species growth hormone secretion appears to be more important than prolactin for galactopoiesis (Machlin, 1973). In the mare the importance of continued prolactin secretion to the maintenance of milk secretion has not been tested, but the fact that prolactin concentrations become basal 1-2 months post partum, while suckling and lactation continue, suggests that prolactin may decline in importance in the later stages of lactation.

Observations of lactating females whose young were removed soon after birth have indicated that the increased release of prolactin seen in lactation is completely dependent on stimuli provided by suckling the young (Grosvenor, Whitworth \& Mena, 1975; Concannon et al., 1978; McNeilly \& Friesen, 1978). In the current study, data from the mare which lost her foal shortly after birth confirm that the presence of the foal is entirely responsible for the increased circulating prolactin seen in lactating mares.

The event which triggers the huge pre-partum increase in circulating prolactin is not known for the mare or other mammalian species. In the last 1-3 days of pregnancy in the mare, there is a cascade of hormonal events, with progesterone and oestrogen concentrations falling (Lovell, Stabenfeldt, Hughes \& Evans, 1975) and an increase in prostaglandin F-2 $\alpha$ just before labour. However, the causal link between these events remains obscure. Further experiments are in progress to examine in more detail the relative timing of these hormonal events in relation to the initiation of parturition and lactation.

In this limited number of mares, there did not appear to be any correlation between the timing of the first post-partum oestrus and its duration, but in the mare which lost her foal (Mare 5) oestrus was early. Also, some of the present results suggest that, as in other species, there may be a role for high concentrations of prolactin in determining the fertility of mares post partum. All the mares showed oestrus and ovulation in the first week post partum; high prolactin concentrations at this time were therefore not able to suppress ovarian activity completely. Furthermore, no marked changes in prolactin concentrations were seen at the time of the first post-partum oestrus. However, in one of the mares (Mare 1) the first oestrous period was followed by an abnormally late rise in progesterone after ovulation. Also, this mare then showed a prolonged anoestrous period with basal progesterone concentrations. This mare had consistently higher prolactin concentrations after foaling than did the other 3 mares with a normal lactation. Although by no means conclusive, this observation does indicate a possible connection between high prolactin and abnormal cyclic activity or anoestrus at this time.

The early post-partum oestrus of the mare which lost her foal at Day 1 post partum suggests that some component of the suckling stimulus, perhaps prolactin, is capable of exerting an inhibitory effect upon the hypothalamic-pituitary axis in the period immediately after foaling.

We thank the HBLB for financial support and Professor C. H. Li for generous donation of horse prolactin standard and antiserum. 


\section{References}

Buttle, H.L., Forsyth, I.A. \& Knaggs, G.S. (1972) Plasma prolactin measured by radioimmunoassay and bioassay in pregnant and lactating goats and the occurrence of a placental lactogen. J. Endocr. 53, 483-491.

Concannon, P.W., Butler, W.R., Hansel, W., Knight, P.J. \& Hamilton, J.M. (1978) Parturition and lactation in the bitch: serum progesterone, cortisol and prolactin. Biol. Reprod. 19, $1113-1118$.

Cowie, A.T., Forsyth, I.A. \& Hart, I.C. (1980) Hormonal Control of Lactation. Springer-Verlag, Berlin.

Davis, S.L., Reichert, L.E. \& Niswender, G.D. (1971) Serum levels of prolactin in sheep as measured by radioimmunoassay. Biol. Reprod. 4, 145-153.

Fell, L.R., Beck, C., Brown, J.M., Catt, K.J., Cumming, I.A. \& Goding, J.R. (1972) Solid-phase radioimmunoassay of ovine prolactin in antibody coated tubes. Prolactin secretion during estradiol treatment, at parturition and during milking. Endocrinology 91, 1329-1336.

Forsyth, I.A., Rossdale, P.D. \& Thomas, C.R. (1975) Studies on milk composition and lactogenic hormones in the mare. J. Reprod. Fert., Suppl. 23, $631-635$.

Grosvenor, C.E., Whitworth, N. \& Mena, F. (1975) Milk secretory response of the conscious lactating rat following intravenous injections of rat prolactin. $J$. Dairy Sci. 58, 1803-1807.

Habener, J.F., Rosenblatt, M., Dee, P.C. \& Potts, J.T. Jr (1979) Cellular processing of preproparathyroid hormone involves rapid hydrolysis of leader sequence. $J$. biol. Chem. 254, 10596-10606.

Kann, G. (1976) Influence of the suppression of the prepartum surge of prolactin by ergocryptine on the milk yield and on the post-partum anoestrus of the nursing ewe. Annls Biol. anim. Biochim. Biophys. 16, 163.

Kann, G., Martinet, J. \& Schirar, A. (1978) Hypothalamic-pituitary control during lactation in sheep. In Control of Ovulation, pp. 319-333. Eds D. B. Crighton, N. B. Haynes, G. R. Foxcroft \& G. E. Lamming. Butterworths, London.

Li, C.H. \& Chung, D. (1983) Studies on prolactin 48: isolation and properties of the hormone from horse pituitary glands. Archs Biochem. Biophys. 220 , 208-213.

Lovell, J.D., Stabenfeldt, G.H., Hughes, J.P. \& Evans, J.W. (1975) Endocrine patterns of the mare at term. J. Reprod. Fert., Suppl. 23, 449-456.
Machlin, L.J. (1973) Effect of growth hormone on milk production and feed utilization in dairy cows. $J$. Dairy Sci. 56, 575-580.

McNeilly, A.S. (1980) Prolactin and the control of gonadotrophin secretion in the female. $J$. Reprod. Fert. 58, 537-549.

McNeilly, A.S. \& Friesen, H.G. (1978) Prolactin during pregnancy and lactation in the rabbit. Endocrinology 102, $1548-1554$.

Munro, C.D., Renton, J.P. \& Butcher, R. (1979) The control of oestrous behaviour in the mare. $J$. Reprod. Fert., Suppl. 27, 217-227.

Nett, T.M., Holtan, D.W. \& Estergreen, V.L. (1975a) Levels of $\mathrm{LH}$, prolactin and oestrogens in the serum of post-partum mares. J. Reprod. Fert., Suppl. 23, 201-206.

Nett, T.M., Holtan, D.W. \& Estergreen, V.L. (1975b) Oestrogens, LH, PMSG and prolactin in serum of pregnant mares. J. Reprod. Fert., Suppl. 23, 457-462.

Nordskog, A.W. \& Clark, R.T. (1945) Ergotism in pregnant sows, female rats and guinea pigs. Am. J. vet. Res. 6, 107-116.

Roser, J.F., Chang, Y., Papkoff, H. \& Li, C.H. (1984) Development and characterization of a homologous radioimmunoassay for horse prolactin. Proc. Soc. exp. Biol. Med. 175, 510-517.

Schams, D., Reinhardt, V. \& Karg, H. (1972) Effects of 2-Br- $\alpha$-ergokryptine on plasma prolactin levels during parturition and onset of lactation in cows. Experientia 28, 697-699.

Shaar, C.J. \& Clemens, J.A. (1972) Inhibition of lactation and prolactin secretion in rats by ergot alkaloids. Endocrinology 90, 285-288.

Shiu, R.P.C., Kelly, P.A. \& Friesen, H.G. (1973) Radioreceptor assay for prolactin and other lactogenic hormones. Science, N.Y. 180, 968-971.

Sullivan, J.J., Turner, P.C., Self, L.C., Gutteridge, H.B. \& Bartlett, R.E. (1975) Survey of reproductive efficiency in the Quarter-horse and Thoroughbred. $J$. Reprod. Fert., Suppl. 23, 315-318.

Taylor, J.C. \& Peaker, M. (1975) The effects of bromocriptine on milk secretion in the rabbit. J. Endocr. 67, $313-314$

Received 31 October 1985 